\title{
Digital technologies: problems and trends
}

\author{
Rizvan Ramzanovich Turluev ${ }^{1}$ and Zalina Musaevna Mutsurova ${ }^{2}$ \\ ${ }^{1}$ Chechen State University, Boulevard Dudaeva Ave., 17, 366007 Grozny, Russia \\ ${ }^{2}$ Chechen State Pedagogical University, st. Kievskaya, 33, 364068 Grozny, Russia
}

\begin{abstract}
If "necessity is the mother of invention", then the 2020 Pandemic (COVID-19) has forced many people around the world to rethink our daily lives from work to school and play. In response to travel bans, school closures, and advice not to gather in large groups and stay away from other people to limit the spread of the virus, many people have turned to digital tools to maintain some semblance of normality. Digitizing our workplaces and education is essential for us to be effective. Those companies that can make good use of technology to continue to evolve and rethink their business model for the future through rapid digital transformation will stay ahead of their competitors. So, the purpose of this article is to consider how digital technologies have transformed since 2020.
\end{abstract}

\section{Main part}

COVID-19 has accelerated the digital transformation of businesses across all industries. Here are the changing aspects of the business you need to adapt to in your digital transition.

The pandemic has accelerated the digital transformation of businesses around the world. Remote working and social distancing efforts have pushed companies to embrace new ways of doing business, measures that have largely included digital tools to communicate, collaborate, and track overall progress. Therefore, it seems overkill to say that digital transformation has been in the spotlight since the coronavirus hit.

The pre-pandemic transformation has mainly been driven by customer needs and the desire for more efficient and flexible processes, but post-pandemic digital transformation is different. Human health and safety, increased communication and collaboration, social distancing and greater adaptability are now critical factors for digital transformation.

Thus, digital transformation is already a more complex process, as it requires us to adapt to new challenges in real time, as well as a faster pace of implementation to ensure business continuity. However, as complex as digital transformation is today, it has become abundantly clear that without it, most companies have no future.

The COVID-19 pandemic not only put society in the face of new global problems, but also caused the development of some technological trends - for example, such as online payments, telemedicine, and robotization. [four]

These technologies are helping to reduce the spread of the coronavirus while also enabling businesses to sustain their operations. In addition, technologies like these can help societies become more flexible and resilient to pandemic and other threats. 
Technology not only plays a critical role in maintaining the sustainable functioning of society in a quarantine and forced isolation during a pandemic, but can also have a longerterm impact after the end of COVID-19.

\section{Online trading and robotic delivery}

At the end of 2002, the SARS outbreak led to a significant increase in e-commerce sites in China, both in the b2b sector and in the b2c sector.

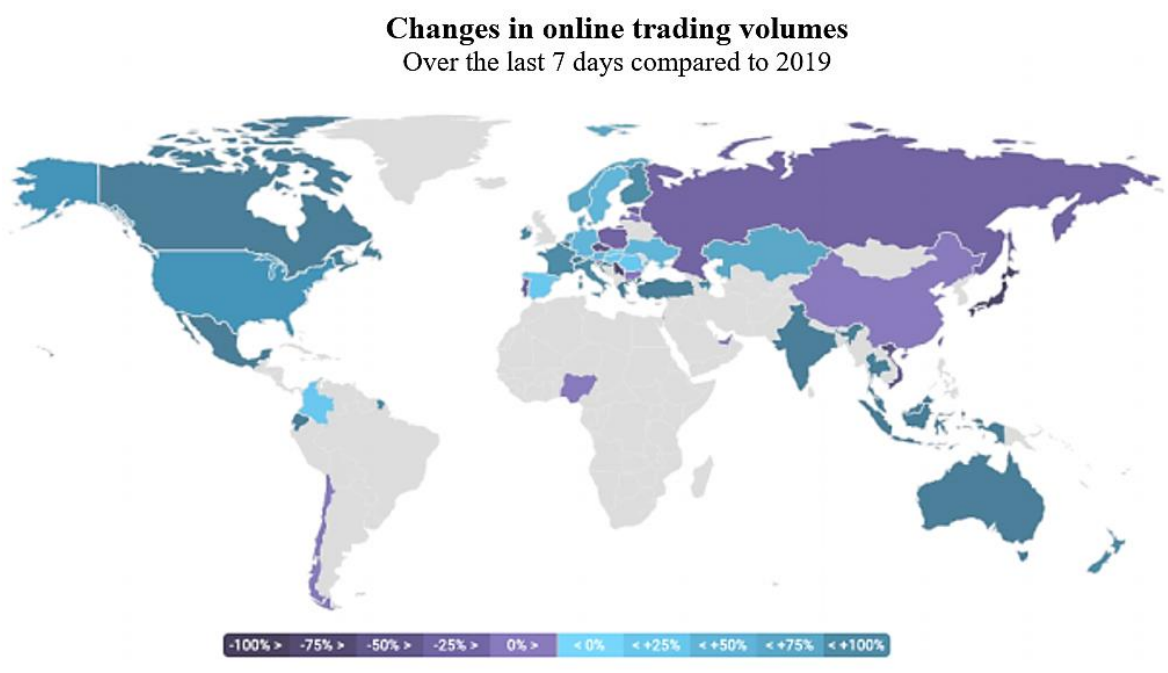

Fig. 1. Changes in online trading volumes

Likewise, COVID-19 has transformed online selling from an added value to an absolute necessity for businesses around the world. For example, some bars and restaurants have continued happy hours promotions for online orders and deliveries during the quarantine period. [2]

Online sales must always be supported by a reliable logistics system. At the same time, courier delivery is not safe from the point of view of the threat of virus transmission. Therefore, many shipping companies, as well as restaurants in the United States, China, Russia and other countries, have launched contactless delivery services, in which the transfer of an order is not carried out from hand to hand, but in a specific location, without direct contact between people.

\section{Electronic and contactless payments}

Cash can help spread the virus. In this regard, the largest banks in the United States, China and South Korea have introduced various measures to ensure the safety of banknotes before they enter circulation. Currently, electronic payments, both with bank cards and electronic wallets, are the recommended payment method to prevent the spread of COVID-19. [four]

However, according to the World Bank, over 1.7 billion people worldwide do not have direct access to electronic payments. Their availability, in particular, depends on the coverage area of the Internet and the availability of the necessary devices for clearing money. 


\section{Remote work}

Many companies have recommended that their employees work from home. Remote working requires technologies such as VPNs (virtual private networks), VoIP (Voice over IP), virtual conferencing, cloud computing, collaboration tools, and even facial recognition technologies to use virtual backgrounds to protect home privacy. Moreover, in addition to preventing the spread of coronavirus, teleworking saves time on the road and provides more flexibility for the employee.

\section{Downloading Remote Work Apps in China}

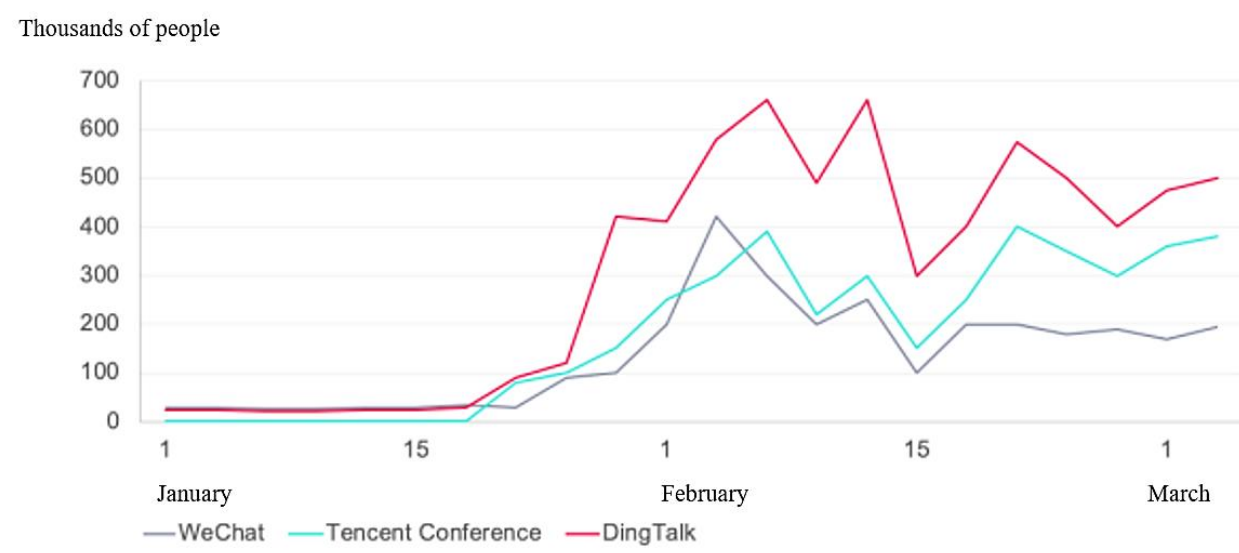

Fig. 2. Downloading Remote Work Apps in China

However, teleworking can also pose additional challenges for both employers and workers. Information security, privacy protection, and timely technical support can be challenging, as the recent class actions against Zoom have shown. [3]

In addition, teleworking can exacerbate conflicts related to labor laws, such as workplace safety or employee tax issues. Workers can also experience problems related to loneliness and a lack of work-life balance. If telecommuting becomes more common after the end of the COVID-19 pandemic, it is likely that employers will have more opportunities to hire cheaper labor from the regions, as well as save on rental costs.

An update of the legal framework will be required, as well as additional psychological research to determine the impact of teleworking on people.

However, not all work can be done from home, leading to inequality. According to the US Bureau of Labor Statistics, about $25 \%$ of workers worked remotely at least occasionally in 2017-2018. At the same time, workers with higher education are 5 times more likely to get positions that allow them to work remotely than workers with secondary education.

Some areas, such as medicine or manufacturing, do not at all imply the possibility of remote work. Data transfer regulations, as well as taxation, may need to be revised if the number of cross-border digital services grows significantly.

\section{Distance learning}

By mid-April 2020, 191 countries announced the suspension of school and university education, affecting at least 1.57 billion students in total. Many educational institutions began to conduct online training in order to avoid disruption of educational processes by quarantine measures. The technologies involved in online learning are similar to those used are used for 
remote work, and also include virtual reality technologies, augmented reality, 3D printing and the use of artificial intelligence robots as teachers.

One of the challenges with distance education is that technology can increase inequalities between people, both in terms of digital readiness and wealth. In addition to this, distance learning can generate economic pressure on parents, most often women, who are forced to stay at home to look after their children, which, in turn, can reduce their productivity at work.

\section{Telemedicine}

Telemedicine can be an effective way to curb the spread of COVID-19 while maintaining primary care. Wearable personal IoT devices can track vital signs. Chatbots can make initial diagnoses based on the symptoms provided by the patient.

However, for countries where the cost of telemedicine is high, it is important that it be covered by health insurance. Among other things, its implementation requires a certain level of technical literacy, as well as a stable Internet connection.

\section{Online entertainment}

While quarantine measures have significantly reduced interpersonal interactions, people's creative efforts have brought entertainment to the online realm. "Cloud raves" and live streaming of concerts are gaining momentum around the world; Chinese filmmakers release films online, museums and cultural heritage sites offer virtual tours. Online video game traffic has skyrocketed since the epidemic began.

\section{Supply chain 4.0}

COVID-19 has led to disruptions in the international supply chain. With the introduction of self-isolation and quarantine measures, many industries were completely closed. While the demand for food and personal protective equipment is growing rapidly, some countries have introduced various restrictive measures on the export of such products. Heavy reliance on paperwork, lack of data transparency, and limited diversity and flexibility have left the existing supply chain vulnerable to any pandemic.

Key technologies of the Fourth Industrial Revolution such as Big Data, cloud computing, Internet of Things and blockchain create a more resilient supply chain management system by improving data accuracy and stimulating data exchange. [one]

\section{3D printing}

To mitigate the supply chain crisis and the impact of export bans, 3D printing technology was deployed. 3D printing allows flexibility in the manufacturing process: a single printer can produce different products depending on the design and materials used in printing, and parts can be produced quickly, without the need for lengthy procurement and delivery processes.

However, mass production using 3D printing faces some hurdles. First, it can run into intellectual property problems if the parts it produces are protected by a patent. Secondly, the production of some products such as surgical masks are subject to regulations that may require lengthy approvals.

Other unresolved issues so far include issues of protection of design rights, its place of origin and impact on trade, as well as liability for the quality of manufactured products related to $3 \mathrm{D}$ printing. 


\section{Robotization and drones}

COVID-19 made the world realize how much we depend on human interactions in all processes. The most affected businesses associated with labor-intensive processes such as retail, food production, industry, logistics.

COVID-19 has given a significant boost to the use of robots and robotics research. In recent weeks, robots have been used in all kinds of processes, from disinfecting surfaces to delivering food to people in quarantine. Drones have also been used for dog walking and delivering goods.

While some reports predict the replacement of many manufacturing jobs with robots, new jobs will be created in the process. At the same time, the authorities must timely provide adequate training and social protection in relation to the workforce to adapt to the ongoing changes.

\section{$105 \mathrm{G}$ and information and communication technology (ICT)}

All of the above technological trends are based on a stable, high-speed and affordable Internet. With $5 \mathrm{G}$ demonstrating its importance in remote surveillance and medical consultation processes, the rollout of $5 \mathrm{G}$ connectivity in Europe has been delayed until it is most needed.

The transition to $5 \mathrm{G}$ will lead to an increase in the cost of relevant devices and communication tariffs. Addressing these issues in ensuring universal access to the Internet will continue to be a challenge amid the worldwide spread of $5 \mathrm{G}$ connectivity.

COVID-19 has demonstrated the importance of digitalization to keep businesses running and everyday life as business as usual in a pandemic. The development of the necessary infrastructure to support the digitalizing world, maintaining relevance against the background of rapidly developing technologies, as well as a people-centered and inclusive approach to managing technology development will be of the utmost importance for both businesses and states in maintaining competitiveness in the post-pandemic world.

An estimated 200 million people will lose their jobs as a result of COVID-19. However, the financial burden most often falls on the most vulnerable members of society. Digitization and the pandemic have accelerated the creation of new jobs. Mitigating the impact on the workforce as well as vulnerable populations is a challenge for all businesses and governments.

Solving this challenge requires not only special attention, but also a timely and humancentered approach.

findings

The coronavirus pandemic has brought many changes. She made us all look for new ways to work, interact and live. This has raised questions about how our societies work and where we want and should invest in the future. She showed us our strengths and highlighted our weaknesses. This presented us with new challenges, not the least of which is trying to find a cure.

The quarantine has dealt a heavy blow to the global economy. According to experts, this year the global economy will lose $8-13 \%$. According to the most optimistic forecasts, only in the fourth quarter the growth rates may return to pre-quarantine levels. Air travel and other industries hardest hit by the epidemic will not recover until 2021. It is obvious that the global economy has already entered a recession phase.

However, in the midst of the epidemic, we are seeing a clear increase in demand for digital services everywhere. Healthcare, education, finance, the entertainment industry, and companies that continue to work remotely are in particular need of digitalization. 
So, Digital is a key component of our collective efforts to fight the virus and support our new ways of living and working during this exceptional time. Digital technology, media and telecommunications play a vital role.

\section{References}

1. E.A. Abramova, M.A. Kapralova, Bulletin of the Ivanovo State University, Series "Economics", 1/2 (39/40) (2019)

2. O.V. Demyanova, Problems of modern economy, 1(33) (2018)

3. Interview to the RIA Novosti agency with the leading economist of the World Economic Forum R. Crotti. M. (2020)

4. Manfred Spitzer. Anti-brain: digital technologies and the brain (2015)

5. M. A. Abrosimova, Information technologies in state and municipal management, 248 (2013)

6. P. V. Bespalov, Akmeological concept of the formation of information technology competence of civil servants, 238 (2015)

7. I.A. Vasilenko, State and municipal management, 496 (2013)

8. L. A. Vasilenko, Outsourcing - innovative personnel technology of public service, 216 (2015) 